\title{
Apropriações da Instrução ao Sósia na análise da atividade de trabalho
}

Alda Karoline Lima da Silva. Universidade Potiguar.

Gimena Pérez Caraballo. Universidade Federal do Rio Grande do Norte.

Miliana Galvão Prestes. Universidade Federal do Rio Grande do Norte.

Débora Guerra Pereira Xavier. Universidade Federal do Rio Grande do Norte.

Jorge Tarcísio da Rocha Falcão. Universidade Federal do Rio Grande do Norte.

Camila Costa Torres. Universidade Federal do Rio Grande do Norte.

\section{Resumo}

Este artigo fundamenta-se em quatro experiências de pesquisa nas quais foi utilizada a técnica de Instrução ao Sósia (IaS) para análise da atividade de trabalho em variados contextos laborais. São apresentadas e discutidas as aplicações da técnica nessas pesquisas norteadas pela abordagem teórica e metodológica da Clínica da Atividade. As experiências mencionadas efetivaram-se em diferentes ambientes laborais - hospitais, universidades, praias - com seus respectivos participantes (profissionais de saúde, professores e trabalhadores informais). O uso da técnica ensejou diversos fenômenos psíquicos, dentre os quais se destaca a reflexão do trabalhador sobre sua atividade, tanto no âmbito da dimensão clínica da atividade de trabalho como na esfera da identificação de competências diante os possíveis desenrolar da atividade. As contribuições oriundas de tais experiências permitem indicar a técnica para futuros estudos em diferentes contextos laborais, o que evidencia amplas possibilidades de utilização.

Palavras-chave: atividade de trabalho; instrução ao sósia; clínica da atividade.

\begin{abstract}
Appropriations of the Instruction to the double in the analysis of work activity. This article is grounded on four research experiences in which has been used the Instruction to the double technique to analyze the work activity in a variety of workplace settings. The applications of the technique are presented and discussed in those researches, guided by the theoretical and methodological approach of the Clinic of Activity. The experiences reported occurred in different working environments - hospitals, universities, beaches - with their participants (health professionals, teachers and informal workers). The use of the technique allow various psychic phenomena, among which stand out the worker's reflection on its activity, in the clinical dimension of work activity, and competence identification dimension in front of possible developments of the activity. Contributions from these experiences allow to indicate the technique for future studies in different work contexts, thereby demonstrating their broad possibilities of use.
\end{abstract}

Keywords: work activity; instruction to the double; clinic of activity.

\section{Resumen}

Apropiaciones de la Instrucción al doble en el análisis de la actividad de trabajo. Este artículo se basa en cuatro experiencias de investigación en las cuales fue utilizada la técnica de Instrucción al doble para el análisis de la actividad de trabajo en contextos laborales variados. Son presentadas y discutidas las aplicaciones de la técnica en esas investigaciones, orientadas por la perspectiva teórica y metodológica de la Clínica de la Actividad. Las experiencias mencionadas se realizaron en diferentes ambientes laborales - hospitales, universidades, playas - con sus respectivos participantes (profesionales de la salud, profesores y trabajadores informales). El uso de la técnica posibilitó diversos fenómenos psíquicos, entre los cuales se destacan la reflexión del trabajador sobre su actividad, tanto en el ámbito de la dimensión clínica de la actividad de trabajo, como en el ámbito referente a la identificación de competencias frente a los posibles desenvolvimientos de la actividad. Las contribuciones oriundas de tales experiencias permiten indicar la técnica para futuros estudios en diferentes contextos laborales, lo que evidencia amplias posibilidades de utilización.

Palabras clave: actividad de trabajo; instrucción al doble; clínica de la actividad. 
A Instrução ao Sósia (laS) é uma técnica que vem sendo amplamente utilizada nos estudos clínicos no campo da Psicologia do Trabalho, notadamente no rol das clínicas do trabalho para a análise da atividade laboral, quanto ao desenvolvimento e aos impedimentos da atividade. Originária do campo da Saúde do Trabalhador teve Ivar Oddone e sua equipe como seus pioneiros, e desde os anos 90 vem sendo retomada pela Clínica da Atividade (C.A.) por meio dos trabalhos de Yves Clot (1995, 1999, 2007, 2010, 2011) e seus colaboradores do Conservatoire National des Arts et Métiers em suas pesquisas sobre a análise da atividade laboral.

O uso da terminologia clínica, como apontam Bendassolli e Soboll (2011), não se associa à ideia primária de trabalhar com problemáticas individuais. A C.A., norteada pelos pressupostos da Psicologia Histórico-Cultural, considera uma articulação cofundante entre o mundo psíquico individual e o mundo social. Para isso, recorre à análise da atividade de trabalho, buscando compreender seu desenvolvimento e seus impedimentos.

Um dos aspectos centrais da C.A. diz respeito ao interesse pelo jogo dialético que se estabelece entre o trabalho prescrito (o que deve ser feito), a atividade real (o que realmente é feito) e o real da atividade. Esse último compreende não apenas o que se faz ou o que se deixa de fazer, mas também o que não se pode fazer, o que se tenta fazer sem conseguir, o que se teria podido ou querido fazer, o que se sonha fazer, o que se faz para não fazer o que deve ser feito, o que se faz sem querer fazer (Clot, 2007; Lhuilier, 2002). Nesse sentido, o artigo apresenta uma análise do uso da laS em quatro pesquisas embasadas pela C.A., cujo cerne é a atividade de trabalho em diferentes categorias ocupacionais. O foco principal deste artigo é apresentar as possibilidades e desafios metodológicos da técnica, não se propondo a apresentação detalhada dos resultados isolados de cada pesquisa.

A técnica de laS vem sendo utilizada nos mais diversos campos de estudo e nas mais variadas atividades profissionais, sendo verificados seus usos em pesquisas com motoboys, profissionais de saúde, cozinheiros, trabalhadores da educação (especialmente professores), pesquisadores, dentre tantas outras categorias, em sua maioria no âmbito da Psicologia do Trabalho (Barros \& Silva, 2013; Mattedi, Barros, \& Carvalho, 2014; Moraes \& Athayde, 2014; Oliveira, 2011) com foco nas questões de sáude, trabalho e subjetividade.

\section{História da Técnica}

A laS faz parte do legado deixado pelo conjunto de pesquisadores, profissionais de saúde e militantes sindicais associados ao chamado Movimento Operário Italiano (MOI), que contava com a liderança técnico-científica do médico e psicólogo Ivar Oddone. Esse método foi desenvolvido a partir da experiência de Oddone junto a Alessandra Re e Gianni Briante com operários da FIAT, em Turim, na década de 1970. De forma mais ampla, o MOI colaborou para a instauração do debate relacionado às formas de produção de conhecimentos no domínio da Psicologia do Trabalho, bem como no campo da Saúde do Trabalhador.

Há no interior desse movimento um questionamento e uma mudança de postura e de percepção dos pesquisadores em relação ao lugar dos trabalhadores na construção do conhecimento produzido sobre sua realidade de trabalho. Oddone, Re e Briante (1981) notaram que já existia uma elaboração crítica a respeito das formas de agir no trabalho e da experiência coletiva em que elas se baseavam, e que as intervenções dos trabalhadores sobre seu trabalho eram anteriores às intervenções dos especialistas. Eles reconheceram algum tipo de "psicologia não escrita" e tácita, que era construída na e pela atividade exercida pelos trabalhadores.

Assim, os trabalhadores passaram de meros detentores de informações que precisam ser coletadas de forma sistemática, para sujeitos providos de singularidades e imersos em um coletivo de trabalho, os quais devem ser protagonistas da experiência de construção da análise sobre o seu trabalho. É justamente essa experiência que possibilita um potencial transformador ao método elaborado e proposto pela equipe de Oddone. Ela torna possível o acesso ao patrimônio tácito anterior de elaborações do trabalhador sobre sua realidade, bem como a reapropriação da capacidade de intervenção sobre o próprio trabalho que, por sua vez, proporciona a ampliação das possibilidades do trabalhador frente a essa realidade.

É nesse contexto que a las é elaborada como uma nova perspectiva de ação-investigação e nela, a experiência torna-se elemento central, na qual as possibilidades de ação na atividade de trabalho tornamse ampliadas. Oddone e a sua equipe desenvolveram assim um novo método, a istruzione per il sosia, no qual o trabalhador deve dar instruções a um "eu auxiliar", a um sósia após receber a seguinte indicação: 
Se ci fosse un'altra persona perfettamente uguale a te dal punto di vista fisico, come gli diresti di comportarsi in fabbrica rispetto alla mansione, ai compagni di lavoro, alla gerarchia aziendale, all'organizzazione sindacale (o ad altre organizzazioni dei lavoratori), in modo tale che non fosse possibile accorgersi che non sei tu ( $^{1}$ (Oddone, Re, \& Briante, 2008, p. 96).

Ao passo que o trabalhador era deslocado do seu lugar naturalizado por meio da suposta situação de substituição por um sósia exigente a quem deveria instruir em mínimos detalhes, a barreira da descrição idealizada sobre o trabalho era vencida e os descompassos entre o trabalho prescrito e o trabalho realizado vinham à tona. Nesse processo, a complexidade da atividade era desvelada e abria espaço para uma avaliação crítica das escolhas feitas em cada situação, o que fornecia aparato para a transformação das estratégias de confrontação da realidade de trabalho (Muniz, Brito, Souza, Athayde, \& Lacomblez, 2013).

\section{Apropriações da Técnica pela Clínica da Atividade}

AC.A. apropriou-se do método dando continuidade aos pressupostos epistemológicos, teóricos e metodológicos da Psicologia Histórico-Cultural desenvolvida pela chamada "troïka" da Escola Russa de Psicologia, integrada por Vygotski, Leontiev e Luria. Dentre eles, destacamos Vygotski (1925/2003, 1927/2010, 1931/2014) pela sua preocupação permanente no que diz respeito aos aspectos metodológicos pertinentes para o estudo do ser humano. Esse autor parte do postulado essencial de que os processos psíquicos encontram sua origem nos contatos sociais e propõe, em consequência, uma abordagem específica que permita estudar e compreender a sociogênese humana.

Nessa busca de novos métodos, Vygotski (1927/2010) estabelece uma distinção entre os métodos ditos "diretos", dominantes em psicologia até os anos 1930 e baseados na experiência imediata, e os métodos ditos "indiretos", que permitem observar o que está presente além da experiência imediata do sujeito. É justamente esse último tipo de método que Vygotski escolhe para suas pesquisas. Para o autor (Vygotski, 1931/2014) trata-se de estudar o desenvolvimento humano e os processos subjacentes de maneira histórica, ou seja, em movimento, em todos os seus processos de desenvolvimento, em todas as suas etapas e através de todas as suas mudanças.
Para essa perspectiva, a experiência do sujeito não seria acessível diretamente, desse modo, torna-se necessário utilizar um método desenvolvimental que confronte o sujeito a uma transformação da sua atividade e é essa provocação do desenvolvimento que permitiria indiretamente estudá-lo. Este é justamente um dos objetivos maiores da metodologia histórico-desenvolvimental da C.A.: oferecer meios para uma transformação regulada da ação e assim poder compreender e esclarecer o modo como essa transformação é processada e organizada.

Nesse sentido, Brandão (2009) reflete acerca de dois aspectos inerentes ao método em C.A.: o primeiro deles diz respeito a tornar real e explícito um universo de elementos implícitos e nem sempre conscientes escolhas, instrumentos, operações, comportamentos, sentimentos, hesitações -, revelando o quanto o trabaIho abriga uma dinâmica psicológica que se desvela por meio de um outro, despindo suas intrínsecas dimensões subjetiva e social. O segundo aspecto refere-se ao efeito de desnaturalização da atividade provocado no sujeito, necessário para o desenrolar de possíveis transformações nele mesmo e na própria atividade.

É precisamente neste postulado em que se baseia o grupo da C.A. ao realizar as intervenções em meio profissional, salientando que é essencial "transformar para compreender". Isto promoveria o desenvolvimento do poder de agir dos profissionais no que diz respeito à atividade de trabalho e às tarefas e missões que lhe foram dadas pela organização.

Assim, com o objetivo de estudar o desenvolvimento do sujeito, a C.A. analisa tanto a tarefa prescrita e a atividade realizada, quanto o real da atividade, salientando que é essencial que o sujeito transforme sua experiência já vivida em objeto de uma nova experiência. Essa concepção inspira-se na ideia Vygotskiana, segundo a qual a consciência é a experiência vivida de uma experiência já vivenciada.

Contudo, para que exista uma religação da experiência, é necessário que inicialmente ela possa desligar-se a fim de se tornar disponível para viver outras experiências. Como explica Clot (2010), nesse processo de desligamento, a tomada de consciência não consiste tanto em descobrir um objeto até então inacessível, mas sim uma redescoberta desse objeto, de sua recriação em um contexto novo.

Assim, configura-se uma situação artificial em que é possível tornar alheia ao sujeito sua própria experiência, a partir do deslocamento de sua atividade em diálogo com o sósia que agora se apropria dela. Esse efeito pode ser 
transformador para a atividade na medida em que pode alterar seu sentido, ao se desvincular de significações antigas e se realizar em novas significações (Clot, 2007).

Dessa forma, no estudo e análise da atividade profissional é necessário identificar o que deve ser feito, o que foi efetivamente feito e também quais as possibilidades que não conseguiram se manifestar nessa atividade. Como aponta Vygotski (1925/2003), o comportamento seria um sistema de reações que venceram em meio a inúmeras outras possíveis diante de uma dada situação, o que significa que algumas dessas reações vão se manifestar na atividade realizada enquanto outras ficarão na obscuridade. Assim, analisar a atividade profissional pela via de métodos "indiretos", como a laS, permite estudar esta atividade no seu desenvolvimento e em suas diferentes manifestações. Uma ilustração destas pesquisas refere-se às diversas manifestações da atividade, dentre elas o aflorar de competências. Julgamos que o estudo dessas não deveria estar desligado do estudo da atividade profissional, e pode ser realizado por meio de uma técnica como a laS.

Constata-se que a literatura relativa ao conceito de competência é abundante e de grande complexidade, uma vez que é um conceito que evolui no tempo através das diferentes disciplinas que se propõem a sua descrição, compreensão e conceitualização. Diferentes contribuições oriundas da literatura francesa (Coulet, 2011; Leplat, 1991; Pastré, 2007; Rogalski, 2007) apontam a necessidade de ir além desse conceito, privilegiando a atividade como foco central da análise. Ao abordar a atividade de trabalho estaria-se também contemplando as competências que nela se manifestam e os recursos que permitem aos trabalhadores agir eficazmente no seu trabalho.

Se admitimos que a atividade é sempre um jogo entre as possibilidades que se expressam (atividade realizada) e as que não se expressam, mas que continuam agindo no sujeito (real da atividade), seria oportuno conceber a atividade como um mundo repleto de possibilidades. Esse mundo inscreve-se necessariamente em uma história e em um contexto que continuamente estão se transformando. É justamente por isso que, junto com Clot (1995), pensamos que as competências fazem parte da história inacabada de um meio profissional.

\section{A Instrução ao Sósia: Definições e Usos}

A laS é um método utilizado na análise do trabaIho, a partir do movimento de coanálise do trabalhador junto ao pesquisador, contribuindo para a compreensão do desenrolar da atividade de trabalho. A técnica consiste em uma instrução, na qual é importante que o trabalhador esteja ciente que não há respostas certas ou erradas, e que o único objetivo é avançar conjuntamente na análise das formas de realizar a atividade (Batista \& Rabelo, 2013). Dada a instrução, deve ser delimitada uma sequência específica de trabalho a que o trabalhador-instrutor esteja habituado. Essa delimitação ajuda ao trabalhador focalizar a experiência nos detalhes da atividade de trabalho.

Nesse processo é fundamental compreender como o sujeito realiza a sua atividade profissional, como ele age nas diferentes situações encontradas e quais caminhos ele encontra para ultrapassar os diferentes obstáculos. Geralmente, no momento da entrevista, o trabalhador dá uma descrição em que se identifica imediatamente o domínio da situação. O pesquisador tentará, então, "desestabilizar" o profissional, colocando questões inesperadas, muitas vezes ingênuas, expressando dúvidas, antecipando e imaginando outras situações, a fim que a instrução não se limite a uma descrição natural e perfeita que impediria de aflorar os diferentes aspectos da atividade profissional. A ideia é que a descrição não fique restrita à tarefa prescrita, mas que apareçam os aspectos que dizem respeito ao que foi efetivamente realizado e ao real da atividade.

No que se refere à posição do sósia na vivência de experimentação criada, Clot $(1999,2007)$ menciona que o sósia-substituto tem todas as dificuldades para recuperar a experiência do trabalhador. A conversação é voltada para a transmissão de instruções, instaurando uma situação dialógica particular, fazendo com que os interlocutores focalizem a descrição na ação, e não nos seus motivos. Estabelece-se assim um processo de coanálise em que o sujeito participa ativamente da construção das informações que vão compor a análise do trabalho.

A função do sósia é dirigir-se ao sujeito para obter dele uma dupla descrição: a da situação em si e a da conduta a manter na situação. Ele não pode ver a situação como o sujeito, pois para esse ela é cotidiana; já para o sósia, a situação é desconhecida e deve ser descoberta. Assim, o sósia solicita ao trabalhador que o guie em sua ação, assumindo naturalmente uma postura de resistência e questionamento em relação ao relato dele.

Desse modo, no decorrer do exercício, o trabaIhador tenta ser aquilo que ele pensa que deveria ser, servindo-se da situação profissional como mediação, como instrumento de ação sobre o sósia. É nesse jogo 
que a situação não ocupa o mesmo lugar na atividade para os dois interlocutores (Clot, 1999, 2007). O sósia busca, sem jamais encontrar, todas as possibilidades e todos os obstáculos da situação que ele não conhece, recolocando o instrutor frente às escolhas que fez, às impossibilidades que sofreu e que o fizeram eleger a saída apresentada.

O sósia, como representante da ação a repetir, é objeto de instruções cuja execução produz um resultado inesperado para o instrutor. Esse resultado é devolvido pela atividade do outro, de modo que a ação fica dividida em duas. Uma nova versão aparece, rival à primeira, instalando um conflito no desenrolar da ação. Nesse ponto, pode-se dizer que transmitir é tornar possível um novo ato.

O trabalho proposto por esse exercício transforma as operações da ação analisada não em instrumento de referência para sua "reprodução", ou para sua "correção" (remediando-as), mas, sobretudo, em instrumento de descoberta de alternativas diversas em que a ação é provocada. Brandão (2009) aponta que, ao ser observado, o participante já realiza psíquica e concretamente sua atividade de maneira diferente; da mesma forma, num momento posterior, o ato de falar sobre tal atividade a modifica ainda mais. Portanto, a presença de um observador possibilita ao sujeito um novo modo de acessar sua atividade, pois ele sai do lugar de observado e passa ao lugar de observador de seu próprio trabalho.

O método solicita um tipo de envolvimento e de abordagem diferente das intervenções conhecidas nos universos de pesquisa. Por parte do pesquisador-sósia, a implicação é, sem dúvida, da ordem do envolvimento, do enfrentamento e da insistência. Para ele, a compreensão da atividade não pode ser passiva, nem deve incorrer no engano de interpretar a atividade (Clot, 2007). A técnica comporta várias fases, as quais devem ser explicadas para que o trabalhador possa compreender o seu papel. Estas etapas consistem em:

a) Momento de sensibilização, que possibilita trocas de conhecimento entre profissional e pesquisador, e de observação sobre a atividade, para provocar no sujeito a vivência de se colocar como "observador" de seu próprio trabalho e não como "observado";

b) Ao escolher a atividade foco de análise, o pesquisador assume a função do sósia, em que é dada a seguinte instrução: "Suponha que eu sou seu sósia e que amanhã eu me encontro em situação de substituí-lo em seu trabalho. Quais são as instruções que você deveria me transmitir a fim de que ninguém se dê conta da substituição?" (Clot, 2007, p. 144);

c) O trabalhador-instrutor auxilia o pesquisador-sósia a perceber em detalhes uma situação que não conhece, recomendando-se que o trabalhador relate a atividade de trabalho em quatro níveis: O que ele faz habitualmente em sua atividade de trabalho; O que ele não faz; O que ele não deveria fazer se for substituído; O que ele poderia fazer, mas não faz;

d) A atividade do sósia consiste basicamente em "resistir" à atividade do instrutor, por meio de questionamentos discursivos. Assim, deve assumir alguns pressupostos, interessando-se principalmente sobre a questão do como, em detrimento a questão do por que;

e) O encontro posterior do sósia com o instrutor ocorre após a transcrição ou edição videografada do material construído na etapa anterior de relato da atividade, confrontando assim as instruções verbalizadas pelo trabalhador a fim de que este possa comentá-las. Este segundo momento também é registrado - em vídeo ou por escrito - gerando um novo material para análise.

Nas pesquisas mencionadas neste artigo, o material foi registrado, videografado e transcrito, e em outros casos, foi apenas registrado e transcrito. Observe-se também que em nenhum dos casos o material foi transcrito pelo trabalhador-instrutor, apenas pelo pesquisador-sósia. Muitas vezes torna-se difícil reunir todas as condições necessárias para que o trabalhador aceite a transcrição da entrevista. Nesse caso e conforme comenta Clot (2011), é preciso organizar as coisas de forma tal a atingir os objetivos estabelecidos. Compreendemos, assim, que a flexibilidade é um dos aspectos que devem ser contemplados no uso da laS sempre que ela não comprometa à essência da técnica, nem aos aspectos éticos e deontológicos. Nos estudos apresentados aqui, o material foi transcrito integralmente pelo pesquisador e foram escolhidos certos trechos dessa transcrição a partir dos quais foi feita a confrontação com o trabalhador, seja em áudio ou em vídeo.

\section{Método}

A pesquisa em C.A. demanda a formação de um ambiente duradouro de análise e de colaboração (participante e pesquisador), necessitando-se estabelecer uma "parceria", na qual os participantes da pesquisa estão 
munidos de ferramentas para refletir sobre sua prática, especificamente sobre sua atividade, e diante disto poder transformá-la. Desse modo, os estudos adotam um posicionamento teórico-metodológico que atribui aos sujeitos "vida e voz", buscando por esse posicionamento estabelecer articulação entre teoria e prática. A articulação assim buscada baseia-se na adoção, por parte dos participantes, de uma postura de coanalistas e protagonistas críticos no processo de construção de conhecimento e problematização de suas realidades de trabalho.

Os métodos indiretos propostos por essa perspectiva, para desvelar o universo de elementos implícitos presentes na relação do trabalhador com sua atividade, valem-se de instrumentos técnicos como registros de falas e imagens sobre a realização da atividade (Instrução ao sósia, Entrevista de Auto-confrontação Simples e Cruzada, conforme Clot, 2010). Tais instrumentos buscam dar ênfase à linguagem como instrumento semiótico que dá suporte para esses instrumentos técnicos.

Acessar o real da atividade é possível a partir do uso da linguagem, mostrar como se faz uma atividade para um outro, em certa medida, alheio a ela, é simultaneamente mostrar e explicar. A passagem pela linguagem transforma a ação, ela é em si uma atividade, não apenas um meio de acesso. Para Bakhtin (1984), retomado por Clot (2010), a linguagem também é um instrumento que permite a coanálise, a análise conjunta em uma situação de construção dialógica, subjetiva e social.

\section{Participantes}

Os quatros estudos discutidos no presente artigo comportaram a participação de 19 trabalhadores e a técnica foi utilizada individualmente, conforme preconizam as devidas instruções de utilização. O grupo de participantes abarcou os seguintes estudos e categorias ocupacionais: professores da Educação à Distância (EAD) do estado do Rio Grande do Norte-RN; trabalhadores informais (especificamente ambulantes) da praia de Ponta Negra em Natal-RN; profissionais da saúde - médicos, enfermeiros, técnicos de enfermagem e auxiliares de serviços gerais de diferentes nacionalidades (brasileiros e uruguaios) e de diferentes municípios (Santana do Livramento-RS e Santa Vitória do Palmar-RS); e finalmente, profissionais da saúde - técnicos de enfermagem do município de Natal.

O perfil dos participantes era diverso no que se refere ao tempo na profissão, idade, sexo e vinculação institucional (público, privado), e a forma de seleção desses foi pelo critério de conveniência e indicação (bola de neve).

\section{Procedimentos de Uso e de Análise da laS}

O uso da laS adquire suas particularidades em função de cada tipo de categoria ocupacional, apresentando-se como um tipo específico de entrevista que demanda explicitação. A participação em laS exige do participante um envolvimento cognitivo e afetivo, notadamente no que se refere à demanda em falar sobre sua atividade de trabalho, seus modos de fazer, suas possibilidades, seus impedimentos e suas afetações no desenrolar da atividade. A deflagração da técnica de laS aqui descrita se iniciou com apresentação da mesma ao participante, de forma a dirimir eventuais dúvidas. Isso feito, é dada a instrução sugerida pela técnica e iniciado o processo de descrição e análise da atividade laboral. A última etapa prevista pelo uso da referida técnica diz respeito à transcrição do material registrado (em vídeo ou apenas áudio), com retorno ao trabalhador para a confrontação do relato, o que será igualmente transcrito e analisado clinicamente.

A análise aqui mencionada é de natureza clínica, envolvendo operações interpretativas de natureza qualitativa, embasadas na teoria da C.A. Tal análise buscou levar em conta as quatro dimensões norteadoras de todo e qualquer processo psicológico superior, conforme Vygotski (1931/2014): dimensões pessoal, impessoal, interpessoal, transpessoal.

\section{Resultados e discussão}

Nesta seção apontaremos as principais possibilidades observadas em seus usos quanto ao processo de análise da atividade de trabalho de um modo amplo, mas quando pertinente poderemos recorrer a exemplos alusivos das especificidades referentes às categorias ocupacionais que fizeram parte das pesquisas aqui indicadas.

A análise da atividade de trabalho proporcionada pela técnica nos permitiu uma interação tanto com os aspectos clínicos da ação, quanto ao estudo de competências envolvidas na atividade. No âmbito clínico da técnica é possível o desenvolvimento da reflexibilidade sobre a atividade de trabalho, o que permite uma dupla reelaboração: da atividade e do trabalhador.

Nas pesquisas menciondas, a laS permitiu um detalhamento da ação, fazendo com que o pesquisador compreendesse a atividade do trabalhador não apenas de modo descritivo, mas produzisse um diálogo com indagações sobre o desenrolar da ação. Desse modo, como apontou Clot (2010), a necessidade do pesquisador de não "naturalizar" a ação é fundamental, sendo seu papel 
criar questionamentos que levem o sujeito a adentrar em uma esfera que vai além da tarefa prescrita.

Como característica típica dessa técnica clínica, uma gama de comportamentos não observáveis sobrepõe-se a uma descrição operacional da atividade. Há na fala do sujeito um desvelar de elementos subjetivos das dimensões mais intrínsecas da dinâmica psicológica do trabalho, que se revela, naquele momento, para outro (pesquisador-sósia) que se disponibiliza a compreender sua atividade de trabalho, não a considerando "natural", mas assumindo uma postura empática quanto às hesitações e aos sentimentos do trabalhador perante seus afetos com sua atuação profissional. Sentimentos mais íntimos da sua relação com seu ofício são expostos, característica difícil de ser apreendida quando o sujeito não se mobiliza com a técnica proposta.

A entrada distinta no ofício pode apontar direcionamentos diferentes quanto às instruções realizadas. Tal característica pode ser observada com os docentes, a exemplo do professor mais experiente, que iniciou sua instrução contextualizando o cenário da EAD, destacando o papel do aluno e do professor naquela modalidade, enquanto o outro (com menos experiência) iniciou com a descrição de uma atividade mais técnica, como o acesso do professor a uma turma virtual, sendo seu relato inicial norteado pelo âmbito da tarefa prescrita.

Com os técnicos de enfermagem que participaram da técnica no município de Natal, o direcionamento quanto à descrição da atividade foi mais homogêneo, seguindo todos uma linha mais focada nas tecnicalidades da atividade. Somente com o desenrolar da laS e com o desenvolvimento das reflexões sobre o ofício foi que surgiram aspectos mais contextuais, tais como, aspectos políticos relacionados ao panorama da saúde no ambiente público e privado, bem como com a categoria profissional e as instâncias de fiscalização e apoio da categoria (conselhos e sindicatos). Fenômenos parecidos foram identificados no caso dos profissionais de saúde atuantes na fronteira Uruguai-Brasil onde os aspectos técnicos da atividade de trabalho, assim como a tarefa prescrita, eram descritos com mais facilidade. Já no que diz respeito à tarefa efetivamente realizada e ao real da atividade, as dificuldades pareciam maiores e foi só com o desenrolar das instruções dadas pelo trabalhador e através dos obstáculos hipotéticos colocados pelo sósia que esses aspectos - notadamente o real da atividade - se manifestaram.

A dimensão clínica da técnica pode ser elucidada pela fala da grande maioria dos participantes destas pesquisas, que elaboram ao longo do diálogo "descobertas" sobre seus sentimentos de incômodo com alguns aspectos da atividade, o que possibilita constatações de possíveis mudanças na sua atividade laboral, em conexão com o coletivo de trabalho e o gênero profissional, aspectos recobertos pela noção de atividade de trabalho tal qual proposta pela C.A. A referida dimensão clínica alude igualmente ao conceito teórico de competências, na acepção não-individualista dada ao mesmo por Zarifian (2001), manifestadas na atividade de trabalho. Dois dos estudos apresentados neste artigo enfatizaram esse aspecto; um deles foi realizado com profissionais de saúde atuantes na fronteira Uruguai-Brasil, e outro com trabalhadores informais da categoria vendedores ambulantes em uma praia urbana do município de Natal-RN.

No caso dos profissionais de saúde atuantes no contexto fronteiriço supracitado, os resultados mostram que esses trabalhadores teriam desenvolvido diversas competências para além das competências técnicas previstas pelo diploma desses profissionais. Dentre elas, observamos competências de descentração, relacionais e linguísticas, nas quais o profissional se descentraria do seu próprio quadro de referências para poder assim "ver" o outro na sua integralidade e propor em consequência um atendimento mais holístico. O paciente é compreendido nas suas diferenças, no que diz respeito à língua e à cultura, mas também no que se refere ao nível socioeconômico e às condições de vida. Essa compreensão integral por parte dos profissionais fazia com que a sua atividade profissional encontrasse menos entraves e $o$ atendimento eficaz dos pacientes fosse assegurado.

As IaS realizadas com os profissionais deste espaço assinalam que seja pela falta de recursos humanos, por empatia ou para alcançar o trabalho bem feito, os trabalhadores iam, às vezes, além da tarefa prescrita pela hierarquia e de suas competências técnicas para garantirem o bom atendimento do paciente. Esse contexto pareceu, assim, desempenhar um papel muito importante no desenvolvimento de competências e na necessidade de ir além do previsto pela formação profissional destes trabalhadores. Pensamos que essa ampliação da atividade profissional pode conduzir a um aumento do poder de agir e do trabalho bem feito, porque além de toda uma série de variáveis que entram em jogo na atividade profissional, os trabalhadores do âmbito da saúde conseguem resolver as situações que se apresentam diante deles e para as quais eles têm que desenvolver outros meios e outras maneiras de agir. 
De um modo geral, pode-se afirmar que a laS possibilitou um lugar privilegiado no estudo das competências subjacentes à atividade de trabalho, apesar do estudo das competências não ser um objetivo direto da C.A. O uso da laS permitiu abordar competências envolvidas no exercício da atividade laboral, o que extrapola o foco especifico da C.A, mas representa uma possiblidade de ampliação de recursos para o ação, permitindo uma dupla visão, tanto para o trabalhador, quanto para o pesquisador acerca dos modos de fazer, dos conhecimentos e habilidades envolvidos no desenrolar da atividade, a qual está permeada por impedimentos colocados em debate durante o processo de instrução. Nesse sentido, é importante destacar a premissa da técnica de que o pesquisador-sósia deve se colocar como "desconhecedor" da atividade, prevendo os obstáculos que ele encontrará num dia de trabalho, propiciando o trabalhador refletir sobre suas escolhas.

A partir dessa ferramenta de acesso aos comportamentos não efetivados foi possível perceber, dentre vários aspectos, algumas limitações que os trabalhadores possuíam em suas atividades. No caso dos trabalhadores ambulantes, a falta de estrutura organizacional e física para atender a alta demanda de clientes em dias de maior movimento no ponto, ou mesmo a lacuna na compreensão de línguas estrangeiras, foram obstáculos relatados que permitiram inferir a lacuna de conhecimentos e habilidades que os faziam redireccionar seus modos de fazer diante tais dificuldades. Portanto, ao aproximar o trabalhador dos obstáculos encontrados em sua atividade foi possível desvelar as inteligências práticas para resolução de problemas do dia a dia de trabalho, fundamentais para compreender a mobilização das competências, as quais são demandadas diante de eventos e problemas a resolver (Zarifian, 2001).

Avalia-se que a proposta da técnica mostrou-se afinada ao referencial teórico adotado, revelando indícios da possibilidade de captar as escolhas não efetivadas pelo trabalhador, as nuances do coletivo e gênero de trabalhadores ainda em formação, a carga afetiva do trabalho, a autoanálise de cada trabalhador, as variadas maneiras de interpretar e enfrentar um evento em situações concretas de trabalho. Tais aspectos possibilitam a abordagem do construto teórico de competência em contextos laborais, de forma dialógica e vinculada a processos de desenvolvimento das funções psicológicas superiores.

\section{Considerações finais}

As contribuições das pesquisas relatadas permitiram-nos compreender que o uso da técnica de laS vem agregar um válido e importante caminho de investigação tanto para objetivos da C.A, como também para o estudo de conhecimentos e competências manifestados nos mais diversos ambientes de trabalho. As quatro experiências citadas contribuem para o entendimento das diversas potencialidades e limites desta técnica, bem como as possíveis adaptações a serem feitas de acordo com cada realidade de trabalho e conforme os diferentes propósitos de pesquisa.

Um aspecto importante por nós identificado, e conforme explicado nas considerações teóricas, é que a laS possibilitou a retomada das ações em um novo contexto. $\mathrm{O}$ deslocamento da experiência já vivida em algumas pessoas tornou-se um meio para viver de outra forma essa experiência. Assim, a laS permitiu o reconhecimento de automatismos, a expressão do efeito de estranheza (res)sentido no momento de dar instruções a um suposto sósia, e notadamente a dificuldade em verbalizar as competências que se exprimem na atividade profissional. Observamos, desta forma, que esses fenômenos psíquicos aparecem em razão deste método indireto e desenvolvimental.

A técnica permitiu também identificar mobilizações clínicas de caráter terapeutizante, à medida que os participantes puderam expor suas ansiedades e inquietudes, produzindo reflexividade no desenvolvimento de sua atividade de trabalho. Para eles, a verbalização da atividade produziu mobilizações afetivas distintas, tendo em vista aspectos como: profissão/ocupação, escolaridade, ambiente laboral, e outros. Uma característica comum das pesquisas apresentadas aqui foi a elaboração do autoconceito de trabalho, o qual possibilita uma reflexão sobre a realização de um trabalho bem feito, os meios para alcançá-lo, os impedimentos do agir e as alternativas formuladas no processo de elucidação do real da atividade.

Por outro lado, no início da aplicação da técnica foi observada a dificuldade dos trabalhadores efetivamente assumirem o papel de instrutor preconizado pela laS. Constatou-se diversas vezes que os participantes saíam da orientação de "instruir um sósia a fazer como você faz" e passavam a se referir à própria atividade falando em primeira pessoa. Atrelado a isso, aponta-se à tendência 
do trabalhador, em um primeiro momento, a relatar apenas sua tarefa prescrita, apresentando o comportamento ideal que o sósia deveria ter. Esse aspecto já foi observado por Oddone, Re e Briante (1981) explicando que nas instruções dadas pelos trabalhadores existia uma tendência a expressar o comportamento ideal, perfeito, e não o comportamento real. Contudo, é possível ir além dessa dificuldade uma vez que o pesquisador vai gradativamente desnaturalizando o relato do trabalhador, fazendo-o refletir também sobre as diversas possibilidades que abarcam o real da atividade.

Podemos dizer que a C.A. por meio dos seus métodos, aqui destacada a laS, nos permite um olhar clínico do âmbito teórico-metodológico da atividade de trabalho, notadamente permite ao pesquisador assumir, mesmo que imaginariamente, o lugar do trabalhador, e nessa relação dialógica adentra na atividade de trabalho deste último. Esse papel de pesquisador-sósia permite que o trabalhador-instrutor possa ao mesmo tempo sair e entrar na sua atividade, em um processo de ir e vir que o faz reverenciá-la e reconstruí-la. Nesse sentido, o trabalhador redescobre a atividade e podemos dizer junto com Clot (2010) que ao redescobri-la, tem a possibilidade de reviver a experiência passada, transformando-a em objeto de uma nova experiência.

Com base nas utilizações frutíferas da laS em diferentes ambientes laborais aqui apresentados (tanto formais, em organizações, com categorias ocupacionais de gênero bem delimitado, como naquelas informais, de fraca articulação dos coletivos de trabalho e/ou em situações de invisibilidade e vulnerabilidade social), sugerimos que o uso da técnica possa ser ampliado para os mais diversos contextos laborais, a fim de que essas experiências de pesquisa agreguem novas possibilidades de utilização, de aproximação com os trabalhadores, de ajustes inovadores e de avanços no estudo da atividade de trabalho.

\section{Referências}

Bakhtin, M. (1984). Esthétique de la création verbale. Paris: Gallimard.

Barros, M. E. B., \& Silva, F. H. (2013). O trabalho do cartógrafo do ponto de vista da atividade. Fractal: Revista de Psicologia, 25(2), 339-356. doi: 10.1590/S1984-02922013000200008

Batista, M., \& Rabelo, L. (2013). Imagine que eu sou seu sósia... aspectos técnicos de um método em clínica da atividade. Cadernos de Psicologia Social do Trabalho, 16(1), 1-8. doi: 10.11606/issn.19810490.v16i1p1-8

Bendassolli, P., \& Sobol, P. (Orgs.) (2011). Clínicas do trabalho: novas perspectivas para compreensão do trabalho na atualidade. São Paulo, SP: Atlas.
Brandão, G. R. (2009). O Método de instrução ao sósia na Clínica da Atividade: reflexões preliminares. In Anais do XIII Colóquio Internacional de Psicossociologia e Sociologia Clínica (pp. 1-12), Belo Horizonte, MG: Autor.

Clot, Y.(1995). Le travail sans l'homme? Pour une psychologie des milieux de travail et de vie. Paris: La Découverte.

Clot, Y. (1999). Ivar Oddone: os instrumentos de ação. Les territoires du travail: les continents de l'expérience, (3), 33-42.

Clot, Y. (2007). A função psicológica do trabalho (2 ed.). Petrópolis, $\mathrm{RJ}$ : Vozes.

Clot, Y. (2010). Trabalho e poder de agir. Belo Horizonte, MG: Fabrefactum.

Clot, Y. (2011). Théorie en clinique de l'activité. In B. Maggi (Org.), Interpréter l'agir: un défi théorique (pp. 17-39). Paris: PUF.

Coulet, J.-C. (2011). La notion de compétence: un modèle pour décrire, évaluer et développer les compétences. Le travail humain, 74(1), 1-30. doi: $10.3917 /$ th. 741.0001

Leplat, J. (1991). Compétence et ergonomie. In R. Amalberti, M. Montmollin, \& J. Theureau (Orgs.), Modèles en analyse du travail (pp. 263-278). Liège: Pierre Mardaga.

Lhuilier, D. (2002). Travail. In J. Barus-Michel, E. Enriquez, \& A. Lévy (Orgs.), Vocabulaire de Psychosociologie (pp. 284-295). Toulouse: Erès.

Mattedi, A. P. V., Barros, M. E. B., \& Carvalho, S. V. (2014). Análise da atividade: profissionais do sexo do parque Moscoso. Mnemosine, 10(2), 108-123.

Moraes, T. D., \& Athayde, M. R. C. (2014). Dimensões do coletivo na atividade de trabalho dos motoboys. Fractal: Revista de Psicologia,26(2), 327-348. doi: 10.1590/1984-0292/906

Muniz, H. P., Brito, J., Souza, K., Athayde, M., \& Lacomblez, M. (2013). Ivar Oddone e sua contribuição para o campo da Saúde do Trabalhador no Brasil. Revista Brasileira de Saúde Ocupacional, 38(128), 280-291. doi: 10.1590/S0303-76572013000200015

Oddone, I., Re, A., \& Briante, G. (1981). Redécouvrir l'expérience ouvrière. Vers une autre psychologie du travail. Paris: Editions Sociales.

Oddone, I., Re, A., \& Briante, G. (2008). Esperienza operaria, conscienza di classe e psicologia del lavoro. Torino: Otto.

Oliveira, S. D. C. (2011). Abordagem clínica da atividade de trabalho do cozinheiro: interação de saberes, gênero profissional e inovação criativa (Dissertação de mestrado). Recuperado de http://repositorio. ufrn.br:8080/jspui/handle/123456789/17503

Pastré, P. (2007). Champs conceptuels et champs professionnels. In M. Merri. (Org.), Activité humaine et conceptualisation: questions à Gérard Vergnaud (pp. 79-86). Toulouse: Presses Universitaires du Mirail.

Rogalski, J. (2007). Situations et schèmes-action et connaissance. In M. Merri. (Org.), Activité humaine et conceptualisation: questions à Gérard Vergnaud (pp. 161-178). Toulouse: Presses Universitaires du Mirail.

Vygotski, L. (2003). Conscience, inconscient, émotions. Paris: La Dispute. (Obra original publicada em 1925)

Vygotski, L. (2010). La signification historique de la crise en psychologie. Paris: La Dispute.(Obra original publicada em 1927)

Vygotski, L. (2014). Histoire du développement des fonctions psychiques supérieures. Paris: La Dispute. (Obra original publicada em 1931)

Zarifian, P. (2001). Objetivo competência: por uma nova lógica. São Paulo, SP: Atlas. 
${ }^{1}$ Se existisse outra pessoa perfeitamente idêntica a você do ponto de vista físico, como você lhe diria para se comportar na fábrica em relação à tarefa, aos colegas de trabalho, à hierarquia e à organização sindical (ou a outras organizações de trabalhadores) de forma que não fosse possível perceber que não se trata de você? (Tradução livre).

Alda Karoline Lima da Silva, Mestre em Psicologia pela Universidade Federal do Rio Grande do Norte (UFRN), é Professora do Mestrado Profissional em Psicologia do Trabalho (MPPOT) da Universidade Potiguar (UnP). Endereço para correspondência: Universidade Potiguar, Av. Engenheiro Roberto Freire, 2184. CEP: 59082-902. Programa de Mestrado Profissional em Psicologia do Trabalho, Natal - RN.

Telefone: (84) 3216-8616. E-mail: aldakarolinel@yahoo.com.br

Gimena Pérez Caraballo, Doutora em Psicologia Pela Université Lyon 2 e pela Universidade Federal do Rio Grande do Norte

(UFRN), é Pesquisadora Associada da Universidade Federal do Rio Grande do Norte (UFRN) E-mail: gimenaz@gmail.com

Miliana Galvão Prestes, Mestre em Psicologia pela Universidade Federal do Rio Grande do Norte (UFRN). E-mail: milianagalvaop@gmail.com

Débora Guerra Pereira Xavier, Mestre em Psicologia, pela Universidade Federal do Rio Grande do Norte (UFRN), é Assistente em administração da Universidade Federal do Rio Grande do Norte (UFRN). E-mail: deboragpx@gmail.com

Jorge Tarcísio da Rocha Falcão, Doutor em Psicologia da Aprendizagem e do Desenvolvimento pela Université de Paris-V/René Descartes/Sciences Humaines - Sorbonne Paris (França), Pós-Doutorado em Psicologia do Trabalho, junto à cadeira de Psicologia do Trabalho do Conservatoire National des Arts et Métiers Paris (França), é Professor Titular da cadeira de Psicologia Cognitiva na Universidade Federal do Rio Grande do Norte (UFRN). E-mail: falcao.jorge@gmail.com

Camila Costa Torres, Doutora em Psicologia pela Universidade de Brasília (UnB), é Professora Adjunta do Departamento de Psicologia da Universidade Federal do Rio Grande do Norte (UFRN). E-mail: pcamilatorres@gmail.com

Recebido em 04.Dez.15

Revisado em 15.Ago.16

Aceito em 31.Dez.16 